\title{
Structural Analysis on the Riveted Hull of the Paddle Steamer Medway Queen
}

\author{
Pushpajah Rajaguru ${ }^{1}$, Peter Mason ${ }^{1}$, Chris Bailey ${ }^{1}$, Stoyan Stoyanov ${ }^{1}$, Wyn Davies ${ }^{2}$, Brian Burton ${ }^{3}$, Bob \\ Barnes $^{3}$, Les Crowder ${ }^{3}$, Robert Stokes ${ }^{3}$ \\ ${ }^{1}$ Centre for Numerical Modelling and Process Analysis, University of Greenwich, London, UK \\ ${ }^{2}$ Wyn Davies 5201 Consultancy, New Milton, Hampshire, UK \\ ${ }^{3}$ Medway Queen Preservation Society, Gillingham, Kent, UK
}

This paper presents modelling and Finite Element Analysis (FEA) simulation studies on the reconstruction of the historic Medway Queen riveted steel ship. The objective of this study is to assess the longitudinal stress in the hull plates of the Medway Queen (MQ) under various sea and load conditions. Detailed stress analysis in the localised riveted joint regions on the hull is also undertaken. A detailed three-dimensional (3D) digitised model is generated and the used to obtain the cross sectional steel profiles of the ship and their section properties. Finite element analysis with structural elements is used to assess shear stress and bending moments of the ship structure. The model predictions for longitudinal stresses in hull plates are combined with stress assessments for the individual rivet joints in different, judged to be most critical, locations along the ship's length. The structural beam model is used to simulate the ship's stress behaviour under hogging and sagging conditions with two different wave heights. Four sets of live loads are also added to the to the simulation cases. From the longitudinal bending moment and shear force of all sixteen simulations cases, twenty extreme locations are identified and average stress on rivets of joints closed to these locations are predicted. Stress values predicted are below the maximum permissible value of $100 \mathrm{Nmm}^{-2}$ specified by British standards BS153 and BS449. In addition, hull plate test samples with various thicknesses of plates connected with various diameter rivet joints are experimentally tested to assess independently the rivet joint strength and validate the failure criteria adopted in the modelling methodology. The test results have agreed favourably with the limits detailed in the standards.

\section{Introduction}

The use of finite element analysis (FEA) techniques is an attractive approach to undertake structural stress analysis of the historic ship and to assess their structural response to different load conditions [1 and 2]. Finite element analysis has become a standard engineering tool for calculation purposes for decades. The FE code utilised for the analysis in ANSYS mechanical APDL [3], which is widely used commercial and academic finite element code for structural and other coupled physics analysis. The modelling studies in this work focus on the structural analysis in rivets of Medway Queen paddle steamer ship which is now under reconstruction. Hull of MQ is subject to loading generated by weight of machinery, passenger loads, fuel etc, and buoyancy force during a voyage. The loading and sea condition such as wave cause vertical and horizontal bending moments, shear forces and torsional moments. Essential information is the prediction of the hull strength during the vertical or longitudinal bending moment which generates the largest stresses on the hull of MQ. The primary objective of this study is to assess the longitudinal stress on the Medway Queen Hull under various sea and load conditions. Key attribute of the ship's design and construction is the riveted steel plate of which the hull of the vessel is made as in Fig 1. The evaluation of shear strength in riveted connections is one of the key issues in the assessment of the MQ steel structures. In this report we present the calculation of shear stresses derived from the global analysis. The approach presented here has the advantage over the complete modelling of the ship and sub modelling [4] of the ship which in contrast is expensive to set up. 

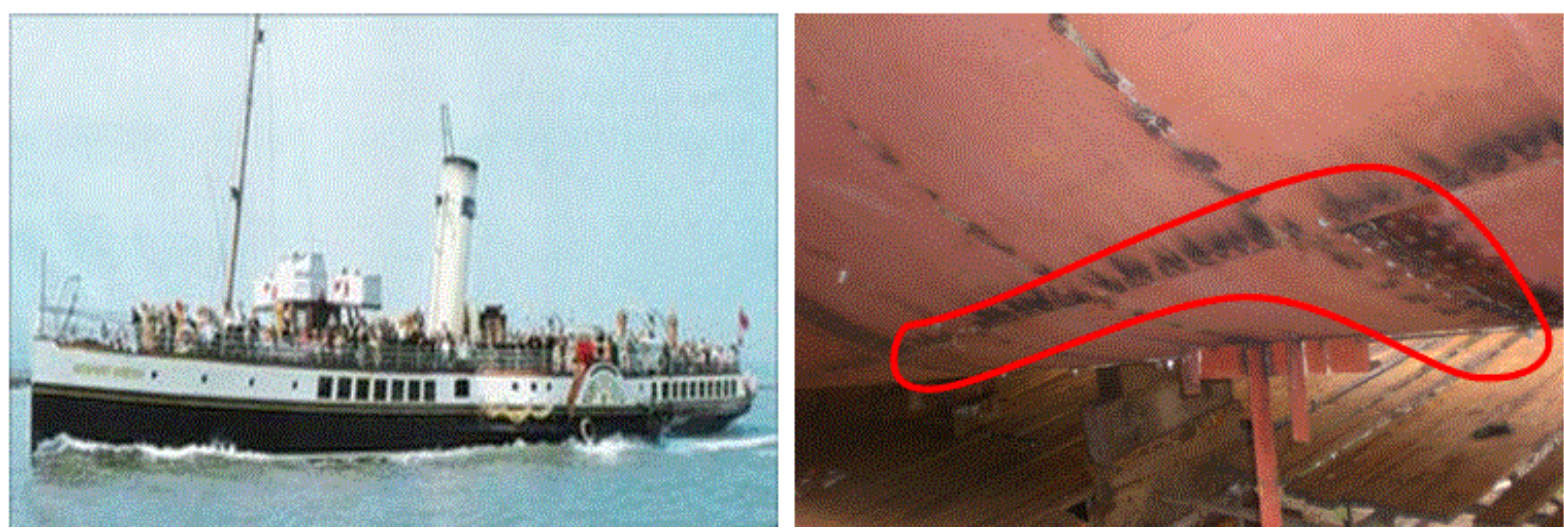

Fig 1: Picture of Medway Queen (left) and a hull region showing riveted plate connections (right)

Many studies have been undertaken by various researchers for the investigation of riveted connections [5- 8]. The installation of hot driven rivets to connect two steel plates involves many variables. Traditionally, after the rivet has been heated to high temperature, the procedure requires that the plain end of the rivet be hammered into a head by a hammer individually. When the hot rivets cools, it shrinks and pulls the plates tightly together. In this way the rivet has residual clamping force and pre-stressing, with a partial slip resistance between attaching plates of the joint are obtained. MQ is constructed by riveting; the primary objective of this study is to assess the longitudinal strength of the MQ under onerous sea and live loads conditions. With this longitudinal strength assessment, more localised strength assessment of the riveted joints of the hull plates.

\subsection{D CAD Model of Medway Queen}

First stage of the stress assessment is to build a 3D model of MQ using the Rhinocerous software [9]. Rhino is a NURB (non uniform rational B - splines) modelling tools for complex shape design. The 3D model of MQ is generated using the offsets data of the MQ and 2D electronic drawings of hull frames provided for this study.
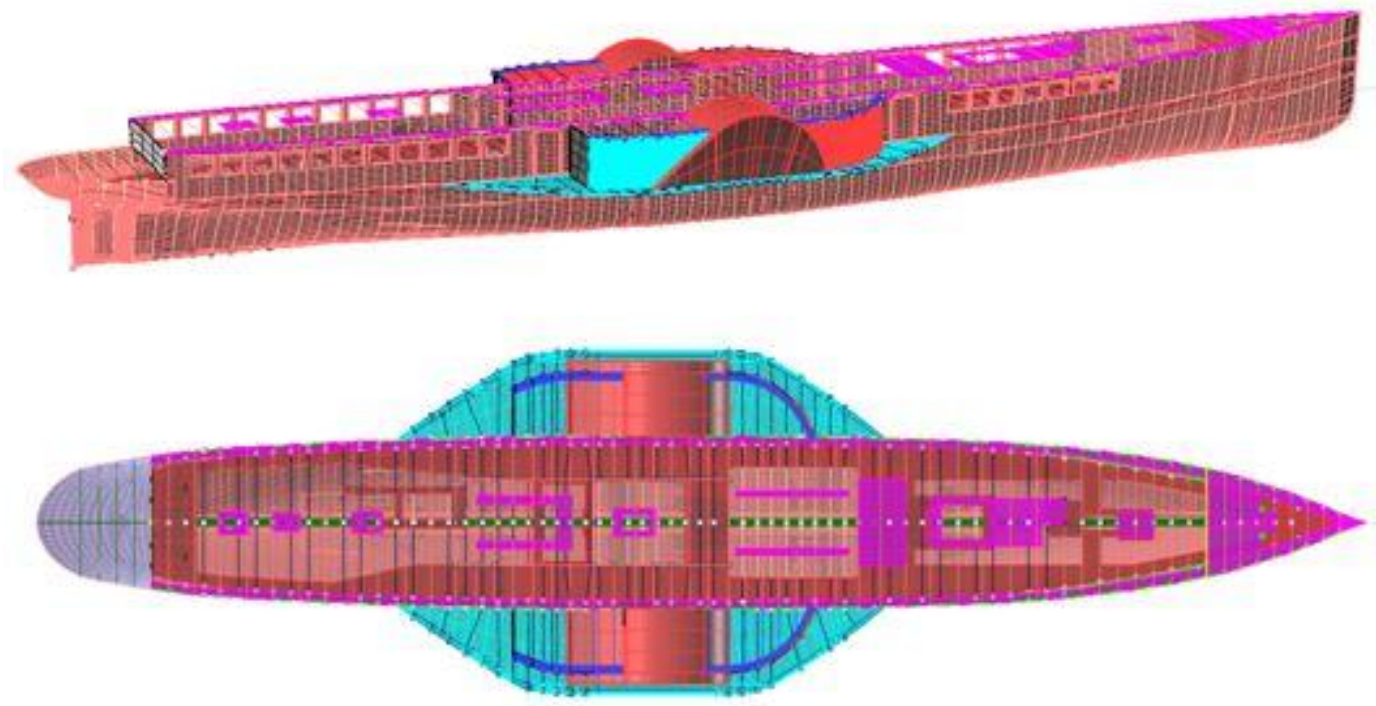

Fig 2: 3D digital model representation of the MQ steel structure (top) and the model bird's eye view (bottom)

Generated 3D electronic geometry as in Fig 2 only represents the steel structures of the ship hull which includes the main and the promenade decks, and also captures the hull frames holding the structure. Steel structure of the sponson is also included in the 3D model. All the frames are represented as lines and plates are represented as shells. 


\subsection{Bonjean Curve of MQ}

Bonjean curves show the relationship between the local draught lines and submerged cross sectional area of the ship. There is one Bonjean curve for each profile (stations). For MQ there are typically 57 profiles from stern to bow as each meter of the ship is profiled for Bonjean curve. At each station we can draw a Bonjean curve of cross sectional area. Using the Rhino model representing the Medway Queen (MQ), cross sectional profile of MQ for every one meter utilised for the Bonjean curve calculation.

\subsection{Weight Distribution of MQ}

Total weight of the ship is 410 tons $(417595.3 \mathrm{Kg})$ which includes the Gross steel weight of 165 tons, Outfit and timber weight of 85 tons and machinery weight of 161 tons [10]. Wet weight of machinery includes not only boiler and reserve feed water, but also bunkers of fuel (either coal or oil). The light weight comprises of hull weight and machinery. Dead weight is the weight of all cargo and passengers, bunkers, fresh and feed water, stores, crew and effects. If weight distribution is known we can use them directly. No individual weight details of the machinery and other parts of MQ are available at the time of the study. Various weight approximation methods such as Constock, Biles, Prohaska, Cole, etc for conventional ships are available in literature [11]. We used one such method namely Prahaska's approximate weight distribution method for segment weights of the MQ. Prohaska proposed a method for a ship with parallel middle body (MQ fulfil this requirement). The weight distribution is a trapezoid on top of a uniform distribution.

For small passenger ship the value of $\mathrm{a}$ and $\mathrm{b}$ are taken as 0.4 and 1.30 [12].To move the position of the centre of weight the bow end and stern ends of the load diagram is adjusted by equal amounts. The Prahaska approximation method does not include the paddle steamer. Unique design of the Medway Queen consists of the most of the heavy machineries are within two bulkheads in the middle. Therefore an adjusted version of Prahaska approximate weight distribution as in Fig 3 is utilised for this study.

\section{Approximate Weight Distribution of Medway}

\section{Queen}

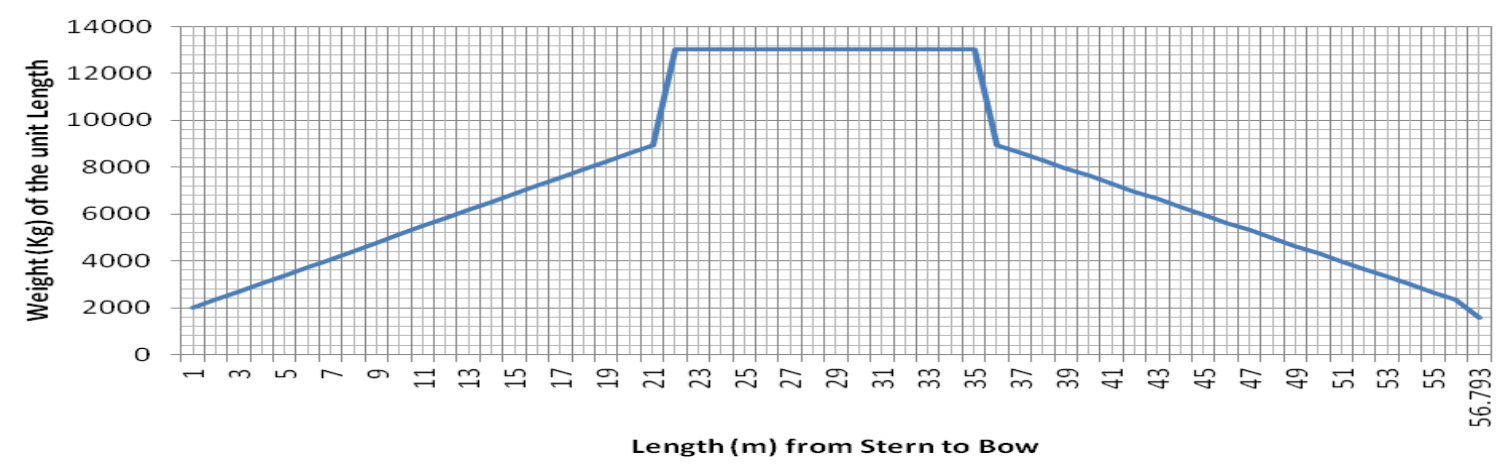

Fig 3: Approximate weight distribution of MQ

\subsection{Wave Conditions}

Two wave shapes are particular significance to the naval architect, the so called troichoidal wave and sinusoidal wave [13]. In this study we only consider the troichoidal wave as its crests are sharper than the troughs. The troichoidal wave curve is generated by a fixed point within a circle rolls along and under a straight line. We choose a trochoidal wave of length $48 \mathrm{~m}$ with heights $1.2 \mathrm{~m}$ and $2 \mathrm{~m}$ for hogging and sagging finite element simulation.

\section{Structural Beam Analysis}

A simple and widely applied technique of analysing the ship structure is beam element analysis [14 and 15]. The mythology we have adopted consists of three steps. The first step is evaluation of various section 
properties of Medway Queen's cross section, especially the Bonjean curve and area moment of inertia about the neutral axis. The second step of analysis is the formulation of the beam element model. Beam element model consists of beam elements representing every meter of the ship and spring elements holding the horizontally placed beams at the mid points. In the formulation of overall stiffness of the beam model, a special consideration is made on the discontinuity of the nodal points which connect two adjacent beam elements. The spring element has highly non linear characteristic representing the buoyancy pressure of the sea water at the hull surface. The third step of this analysis is obtaining the FEA results of shear force and bending moments of the beam model representing the ship structure. This methodology for overall ship structural analysis is associated with practical model development times and analysis computational cost. The modelling methodology is illustrated in Fig 4.


Fig 4: Beam element analysis methodology for longitudinal strength assessment of MQ

First stage of the analysis is obtaining the Bonjean curve of cross sectional profile for every meter of the ship from stern to bow as in Section 2.2. Additionally area moment of inertia of the mid section of every meter length of the ship is obtained. In Rhinocerous cross sectional steel structure profile of the hull plate and decks are generated and from these cross sectional profile area moment of inertia is calculated. These data are assigned to the corresponding beam element representing the part of the ship structure. We choose 2D beam element 
(Beam 54) in ANSYS. Bonjean data is assigned to corresponding spring element (COMBIN 39). The beam element is a uniaxial element with tension, compression and bending capabilities. The element has three degrees of freedom at each node. Therefore the model formed by this element can undergo vertical bending modes. The required data for this element are second moment of area, cross sectional area of the ship structure, shear area, centre of gravity of the cross sectional profile of the ship. Required data for spring element is displacement and force curve data can be obtained from the Bonjean curve.

The MCA (Maritime and Coastguard Authority) requirement for Medway Queen to be sea worthy structure is it has to withstand the pressure caused by the sea condition and the live loads. For this study we choose four set of the live loads as 12, 50, 250 and 993 passengers. For hogging cases passenger are divided into two equal group and one group is packed closed to the bow section of the ship and the other group is packed close to the stern part of the ship. For sagging case all the passengers are packed in the middle part of the ship. In this simulation passengers can be placed on the communal area (main and promenade decks space). Every square meter communal area can be packed with 5.7 passengers with each passenger weight is taken as $85 \mathrm{~kg}$ according to MCA requirements. With the four sets of live loads and two sea conditions such as hogging and sagging and two wave heights, there are sixteen simulation scenarios are set up in beam element simulation.

\subsection{Beam Element Analysis Results}

From beam element simulation various quantities are obtained from sixteen simulations scenarios. Primarily the quantities shear force, bending moment and vertical displacement are obtained from these sixteen finite element simulations. From the beam element analysis models representing the MQ for all the sixteen testing scenarios mentioned in the Section 1.6, displacement (depth of immersion) curve is obtained. Corresponding depth of immersion of the two testing scenarios are plotted in Fig 5.

Similarly from the beam element analysis models representing the MQ for all the sixteen testing scenarios bending moments are obtained. Some cases of bending moment are listed in Fig 6. Sample of modelling results for the two ship conditions with $2 \mathrm{~m}$ wave height, and 250 and 993 passenger live load under hogging ship conditions results in larger bending moments compared with the sagging case. The change of live load from 250 to 993 passengers increases the ship's bending moment by $34 \%$ for the sagging and by $44 \%$ for the hogging Similarly from the beam element analysis models for all the sixteen simulation setups longitudinal shear force are also obtained. Corresponding shear of some cases are plotted in Fig 7. Sample of modelling results for the two ship conditions with $2 \mathrm{~m}$ wave height, and 250 and 993 passenger live load under sagging ship conditions results in larger shear force compared with the hogging case. The increase of live load from 250 to 993 passengers increase the ship shear force by $46 \%$ for the sagging and by $33 \%$ for the hogging


Fig 5: Depth of immersion of MQ for 993 passengers on board in hogging scenario (left) and sagging scenario (right) on $2 \mathrm{~m}$ wave with wave length is equal to $48 \mathrm{~m}$. 

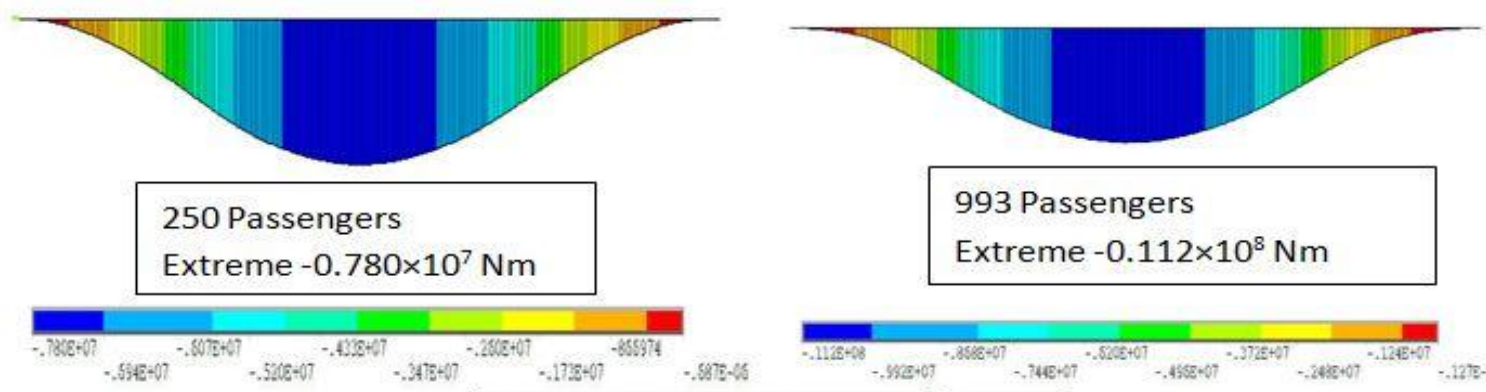

993 Passengers
Extreme $-0.112 \times 10^{8} \mathrm{Nm}$
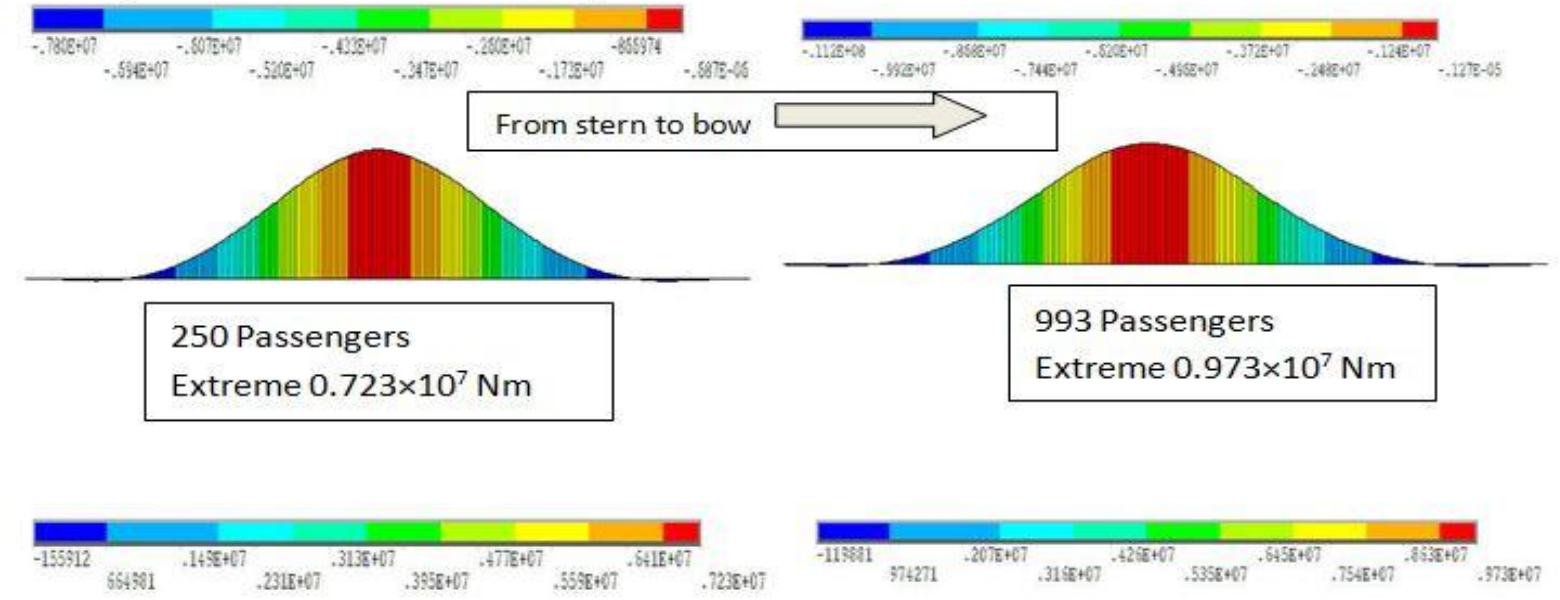

Fig 6: Longitudinal bending moment on $2 \mathrm{~m}$ wave in hogging with 250 passengers (top left), 993 passengers (top right) and in sagging with 250 passengers (bottom left) and with 993 passengers (bottom right)


Fig 7: Shear force plot on $2 \mathrm{~m}$ wave in hogging with 250 passengers (top left), 993 passengers (top right) and in sagging with 250 passengers (bottom left) and with 993 passengers (bottom right) 


\subsection{Medway Queen Hull Strength Assessment}

Forces acting on a ship should be representative of total the sum of the weight of the ship. The mass per unit length at some point is $m$ and the immersed cross sectional area is $a$, then at that point we have:

- $\quad$ Buoyancy per unit length = $\rho g a$

- Weight per unit length $=m g$

- $\quad$ Net force per unit length $=\rho g a-m g$

Net loading is integrated along length of the ship will yield the shear force

Shear force $=\int(\rho g a-m g) d x$

Integrating the shear force along the length of the ship gives the longitudinal bending moment, that is

Longitudinal bending moment, $\mathrm{M}=\int S d x=\iint(\rho g a-m g) d x d x$

Using the shear force and bending moments it is necessary to find the stresses in the ship structure and the overall deflection of the hull. For a beam in which the bending moment at some point $\mathrm{x}$ from one end is $M$, the stress $\sigma$ at distance $z$ from the neutral axis of the section is given by

$\sigma=\frac{M z}{I}=\frac{M}{Z}$

Where $I$ is the second moment of area about the neutral axis of the section at $\mathrm{x}$ and $Z=I / z$ is called the section modulus.

Based on the Medway Queen FEA simulation results, we identified twenty critical locations where the longitudinal bending moment and shear force has extreme values. At these locations, we focused our attention on the assessment of the average stress on the rivets of joints. For calculation of the working stresses in the hull plates and rivets, for each load cases as analysed with the beam element model, we obtain the bending moment $\mathrm{M}(\mathrm{x})$ and the shear stress $\mathrm{Q}(\mathrm{x})$. With these model predictions, stresses in hull plates at any section are possible to evaluate from the following equations:

- Longitudinal direct stress in hull plate $\sigma_{a}=\frac{M(x) y}{I_{y y}}$

- Shear stress in hull plate $\tau_{a}=Q(x) \frac{1}{2 t} \frac{A \bar{y}}{I_{y y}}$

where Iyy - the area moment of inertia about the neutral axis, A - area under the rivet line, $\bar{y}$ - is the distance between the centroid of the cross sectional profile and the centroid of the area under the rivet line, and $\mathrm{y}-$ is the distance between the rivets joint and the centroid of the cross sectional profile.

For transverse rivet joints

Transverse rivet joints of MQ hull is butt jointed with two rows of riveting on each plates. 
Longitudinal direct stress on the plate between two adjacent rivets, $\sigma_{a}^{\text {rivet }}=\sigma_{a}\left(\frac{s}{s-d}\right)$

and similarly shear stress on the plate between two adjacent rivets, $\tau_{a}^{\text {rivet }}=\tau_{a}\left(\frac{s}{s-d}\right)$

where $s$ - the distance between two adjacent rivets and $d$ - the diameter of the rivet.

Von mises stress the plate between two adjacent rivets, $\sigma_{e_{a}^{\prime}}^{\prime}=\sqrt{\sigma_{a}^{\prime 2}+3 \tau_{a}^{\prime 2}}$

\section{For longitudinal rivet joints}

The longitudinal rivet joints are lap jointed with one row of riveting connecting two plates.

Longitudinal direct stress on the plate between two adjacent rivets, $\sigma_{a}^{\text {rivet }}=\sigma_{a}\left(\frac{s}{s-d}\right)$

and similarly shear stress on the plate between two adjacent rivets, $\tau_{a}^{\text {rivet }}=\tau_{a}\left(\frac{s}{s-d}\right)$

\section{$\underline{\text { Loads on rivet for transverse joint }}$}

Longitudinal shear force per rivet $L_{\text {Longitudianl Shear }}=\frac{\sigma_{a} t s}{n}$

Where $n=$ number of rows of rivets carrying load and $t-$ the thickness of the plate

And similarly shear force per rivet $L_{\text {Shear }}=\tau_{a} t s$

Resultant shear load per rivet $L_{\text {Resultant }}=\sqrt{L_{\text {Longitudinalshear }}^{2}+L_{\text {Shear }}^{2}}$

$\underline{\text { Loads on rivet for Longitudinal Joints }}$

Longitudinal shear load per rivet $L_{\text {Longitudinal Shear }}=\tau_{a} t s$

And transverse shear load per rivet $L_{\text {Shear }}=\frac{w}{2} s$

Where $\mathrm{w}=$ weight per unit length above the rivet joint

Resultant shear load per rivet $L_{\text {Resultant }}=\sqrt{L_{\text {Longitudinal shear }}^{2}+L_{\text {Shear }}^{2}}$

Average stress on the rivet $=\frac{\text { Resultant shear load per rivet }}{\pi \times(\text { radious of rivet })^{2}}$

The average stresses on longitudinal joints are plotted against rivet lines from bottom line to top rivet lines on the hull. The numbering is set as one belongs to the first longitudinal row from the bottom and two belong to the second longitudinal row from the bottom and so on. Similarly the plots of average stresses on the transverse 
joints are plotted against rivets on vertical line. The numbering is set as one belongs to the rivet closer to the bottom and two belong to the rivet next closer to the bottom.

\subsection{Loads on Rivets by Beam Element analysis}

Average stress on rivet for each joint is calculated at the critical twenty locations using the analysis proposed above. The plots of average stress value on longitudinal joint are on Fig 8 and the plots of average stress values on transverse joints is on Fig 9.

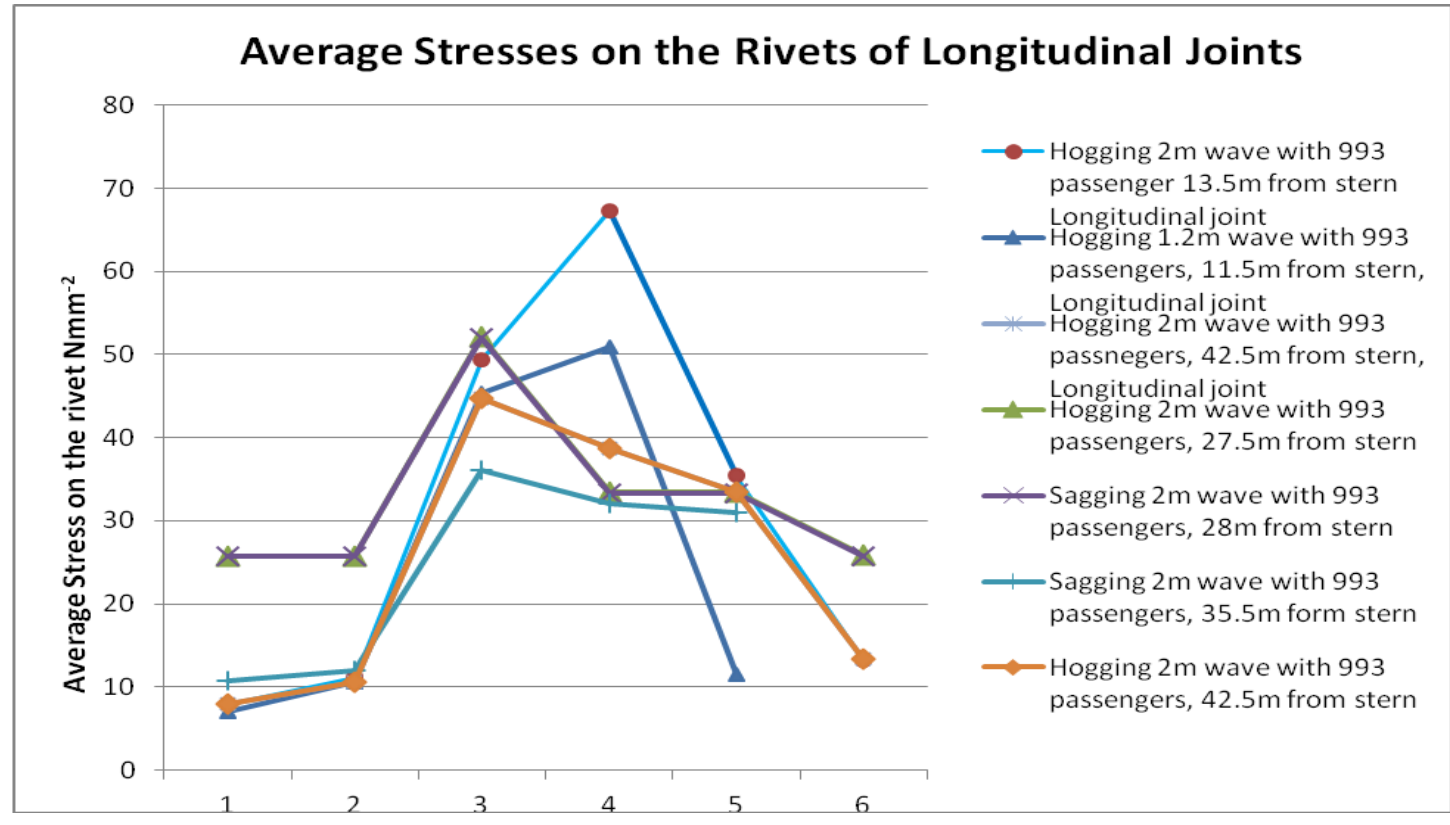

Fig 8: The plots of average stresses on the longitudinal joints

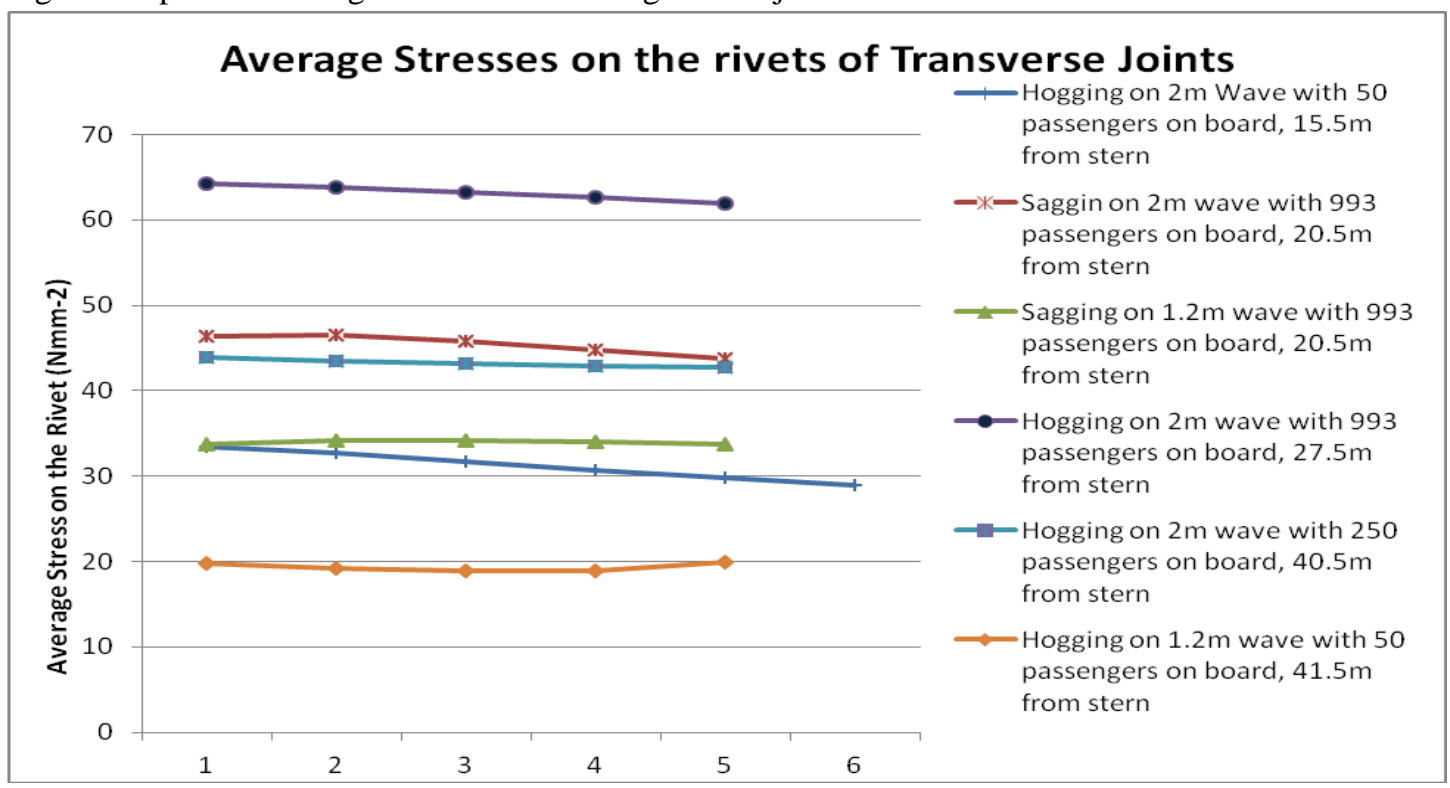

Fig 9: The plots of average stresses on the transverse joints

This maximum average stress on a transverse joint is $64.24 \mathrm{Nmm}^{-2}$ at a distance about $1 / 2$ part of the length of the ship from stern. For longitudinal joints the maximum average stress is $67 \mathrm{Nmm}^{-2}$ and this maximum average stress on longitudinal joint is at a rivet on a joint located at $13.5 \mathrm{~m}$ from the stern. The average stresses plot on longitudinal rivet joints as in Fig 8 has a sudden jump on the curve which is caused by the smaller diameter rivet at that particular joint in contrast to slightly larger diameter of rivets on other longitudianl joints. Obviously larger number of passenger loads in sea condition with large wave height tends to generate larger average stresses. The average stresses on both plots are influenced by the passenger numbers and wave heights. Main 
finding in both plots is the hogging tends to generate larger average stresses in comparison with sagging case with same passeneger load and wave height.

\section{Experimental Validation of Riveted Plate}

Experimental tests have also been performed as part of validation process of the riveted steel plate. Real sample specimen of steel plate with various thicknesses and riveted by various diameter rivets that were representing the hull plate are used for this purpose as in Fig 10. The purpose of the testing of sample joints was to make sure that epoxy treatment of the faying surfaces which is intended to eliminate the need for caulking did not reduce the strength of the joints. The epoxy treatment is a modern approach to replace the caulking procedure in riveting. So we tested rivet joints sample with and without the epoxy coating prior to riveting.
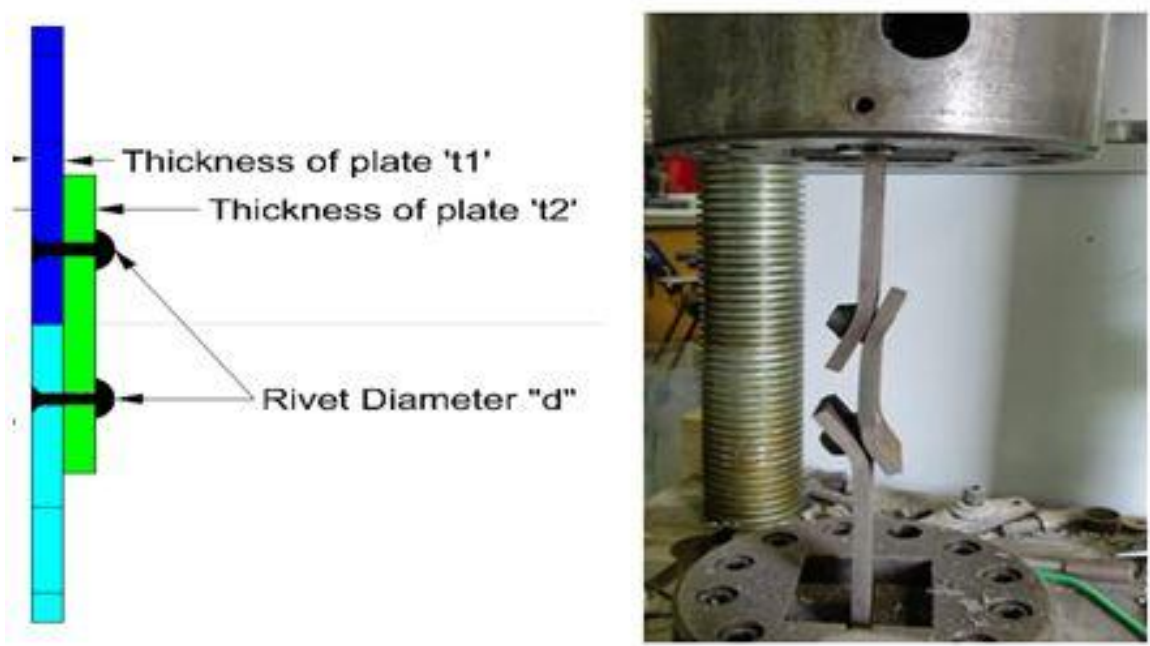

Fig 10: Sample specimen of riveted plate (left) and tensile machine experiment (right)

Summary of tensile test machine on shear test on six rivet joint specimens are listed on the Table 1.

Table 1: Tensile experiment results for rivet joint samples for various plates and rivet diameter thicknesses

\begin{tabular}{|c|c|c|c|c|c|}
\hline $\begin{array}{l}\text { Rivet diameter } \\
\text { ' } d \text { ' }\end{array}$ & $\begin{array}{l}\text { Thickness of } \\
\text { base plate 't1' } \\
(\mathrm{mm})\end{array}$ & $\begin{array}{l}\text { Thickness of } \\
\text { plate 't2' }(\mathrm{mm})\end{array}$ & $\begin{array}{l}\text { Load at onset } \\
\text { on nonlinear } \\
\text { response }(\mathrm{KN})\end{array}$ & $\begin{array}{l}\text { Area of rivet } \\
\left(\mathrm{mm}^{2}\right)\end{array}$ & $\begin{array}{l}\text { Notional stress } \\
\text { in rivet } \\
\left(\mathrm{N} / \mathbf{m m}^{2}\right)\end{array}$ \\
\hline $1 / 2 ،$ & 5 & 5 & 30 & 123 & 244 \\
\hline 1/2"(Ероху) & 5 & 5 & 30 & 123 & 244 \\
\hline $5 / 8 “$ & 5 & 6 & 26 & 198 & 131 \\
\hline 5/8“(Ероху) & 5 & 6 & 26 & 198 & 131 \\
\hline $5 / 8^{\prime 6}$ & 6 & 6 & 30 & 198 & 151 \\
\hline 5/8“(Еpoxy) & 6 & 6 & 30 & 198 & 151 \\
\hline $5 / 8 “$ & 8 & 10 & 38 & 198 & 192 \\
\hline 5/8“(Ероху) & 8 & 10 & 38 & 198 & 192 \\
\hline $3 / 4$ “ & 8 & 10 & 40 & 283 & 141 \\
\hline 3/4“(Ероху) & 8 & 10 & 40 & 283 & 141 \\
\hline $3 / 4$ “ & 10 & 10 & 42 & 283 & 148 \\
\hline 3/4“(Еpoxy) & 10 & 10 & 42 & 283 & 148 \\
\hline
\end{tabular}

The notional stress on all test results indicates that they are dependent on the plate thicknesses as well as rivet diameters. The results also indicate that the onset of non linear behaviour is associated with yielding of the plates rather than pure shear yielding of the rivet material. Maximum allowable stress on any sample specimen 
is $130 \mathrm{Nmm}^{-2}$. The maximum permissible stress value on the rivet specified according to BS153 [16] as $100.03 \mathrm{Nmm}^{-2}$ and according to BS449 [16] as $100.38 \mathrm{Nmm}^{-2}$. The main conclusion of the results is that the epoxy seems to make no difference to the strength of the rivet joints. The joints failed by the onset of yield in the plates, but the rivets showed no noticeable distortion even at complete failure. This indicates that the joint plates were on the small side for loads. And also applied shear loads generated from the finite element simulation in rivets are much less than $100 \mathrm{Nmm}^{-2}$, hence we can reasonably conclude that the rivet joints are all safe.

\section{Conclusion}

Stresses of rivets on the joints connecting the hull plates are predicted using finite element discretisation based modelling approach. Both transverse and longitudinal rivet joints are subject to stress calculations. A beam element modelling technique is utilised to assess the longitudinal bending moment and shear stress on the ship due to onerous sea condition and various live loads. The beam element model represents the ship under hogging and sagging conditions with wave height of $1.2 \mathrm{~m}$ and $2 \mathrm{~m}$ with wave length as $48 \mathrm{~m}$ is simulated. Live loads consists of 12, 50, 250 and 993 passengers with passenger weight is assumed as $85 \mathrm{~kg}$. Sixteen simulation scenarios are simulated and the results for longitudinal bending moment and shear force for all the sixteen scenarios are obtained. Based on the longitudinal bending moment and shear force of all sixteen simulations, twenty extreme locations are identified at which one of these quantities (longitudinal bending moment and shear force) is maximum value. Average stress on rivets of joints closed to these twenty locations is predicted. The results indicate that all the stresses predicted at these twenty locations are below the maximum permissible value of $100 \mathrm{Nmm}^{-2}$. Horizontal axis of the plot of the average stresses on rivets of longitudinal joints represents the rivet joint from the bottom joint and then predicting the upward joints. Each plots of average stress for longitudinal rivet joint has a spike, which is caused by the small diameter 0.5 inch rivet at that joint in contrast to bigger diameter rivets (5/8 inches, $3 / 4$ inches) elsewhere. Our main conclusion is that average stresses on rivets are well below the permissible value. A tensile machine experiment carried out on sample specimen of riveted plate with various dimensions of plate thicknesses and various diameters of rivets to verify the maximum permissible stress confirms the limit after which plate exhibits non linear behaviour. From the tensile test experiment, maximum permissible stress in rivets is identified as $130 \mathrm{Nmm}^{-2}$ which is well above the applied shear stress.

\section{References}

1. S. Stoyanov, P. Mason and C. Bailey, Smeared Shell Modelling Approach for Structural Analysis of Heritage Composite Structures - An application to the Cutty Sark conservation, Computers and Structures, Vol 88, pp. 649-663, 2010

2. Robert E. Melchers and Richard Hough, Modelling Complex Engineering Structures, ASCE press, 2007

3. ANSYS® Academic Research, Release 12.0, ANSYS, Inc

4. Geior, A., Grundy, P., Cannon, S., Nguyen, V., Advanced Finite Element Techniques for Hull Structural Analysis, Proceedings of $8^{\text {th }}$ international offshore and polar engineering conference, 4 , Montreal, Canada, 1988

5. R. A. Hechtman, A Study of the Effects of Heating and Driving Conditions on Hot Driven Structural Steel Rivets, Off. of nav. res. Project, University of Illinois, 1948

6. L. Schenker, C. G. Salmon and B. G. Johnston, Structural Steel Connections, AFSWP report, no 352, Ann Arbor, Department of Civil Engineering, University of Michigan, 1954

7. A. Hrennikoff, Work of Rivets in Riveted Joints, Trans ASCE, 1934, Vol 99, pp. 437-449 
8. G. L. Kulak, J. W. Fisher, and J. H. A. Struik, Guide to Design Criteria for Bolted and Riveted Joints, $2^{\text {nd }}$ edition, New York, John Wiley \& Sons, 1987

9. Rhinoceros, Release 4.0, http://www.rhino3d.com/

10. Medway Queen Project Meeting Report, Annex B, MCA Meeting $31^{\text {st }}$ July 2007-08-02

11. D. L. Hansch, Methods of Determining the Longitudinal Weight Distribution of a Ship, Northrop Grumman Newport News

12. Munro Smith, Applied Naval Architecture, Longmans Inc, 1967

13. Eric C Tupper, Introduction to Naval Architecture, $4^{\text {th }}$ edition, Elsevier Publication, 2004

14. Kawai Tadhiko, The Application of Finite Element Methods to Ship Structures, Computers and Structures, Vol 3 (5), 1973, pp 1175 - 1194

15. Naar, H., Varsta, P., Kujala, P., A Theory of Coupled Beams for Strength Assessment of Passenger Ships, Marine Structures, Vol 17, 2004, pp 590 - 611

16. BS 153, Specification for Steel Girder Bridges, Part 3B, 1958, British Standard Institute

17. BS 449, Specifications for the Use of Structural Steel in Building, Part 2, 1969, British Standard Institute 